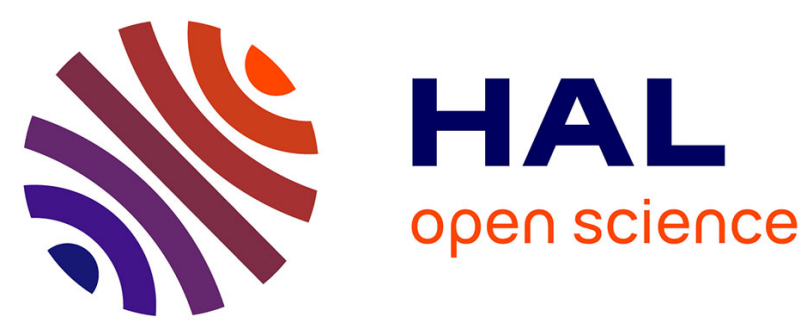

\title{
Flow process conditions to control the void fraction of Thud foams in static mixers
}

\author{
M. Laporte, C. Loisel, D. Della Valle, Alain Riaublanc, A. Montillet
}

\section{To cite this version:}

M. Laporte, C. Loisel, D. Della Valle, Alain Riaublanc, A. Montillet. Flow process conditions to control the void fraction of Thud foams in static mixers. Journal of Food Engineering, 2014, 128, pp.119-126. 10.1016/j.jfoodeng.2013.12.017 . hal-02640902

\section{HAL Id: hal-02640902 \\ https://hal.inrae.fr/hal-02640902}

Submitted on 29 Jul 2021

HAL is a multi-disciplinary open access archive for the deposit and dissemination of scientific research documents, whether they are published or not. The documents may come from teaching and research institutions in France or abroad, or from public or private research centers.
L'archive ouverte pluridisciplinaire HAL, est destinée au dépôt et à la diffusion de documents scientifiques de niveau recherche, publiés ou non, émanant des établissements d'enseignement et de recherche français ou étrangers, des laboratoires publics ou privés.

\section{(c)(1)}

Distributed under a Creative Commons Attribution| 4.0 International License 


\title{
Flow process conditions to control the void fraction of food foams in static mixers M. Laporte ${ }^{\mathrm{a}, \mathrm{b}}$, C. Loisel ${ }^{\mathrm{b}}$, D. Della Valle ${ }^{\mathrm{b}, \mathrm{d}}$, A. Riaublanc ${ }^{\mathrm{c}}$, A. Montillet ${ }^{\mathrm{a}, *}$
}

\author{
a LUNAM Université, Université de Nantes, CNRS, GEPEA, UMR6144, BP 406, 44602 Saint-Nazaire, France \\ ${ }^{\mathrm{b}}$ ONIRIS, BP 82225, 44322 Nantes, France \\ ${ }^{\mathrm{C}}$ UR1268 Biopolymères, Interactions, Assemblages, INRA, 44316 Nantes, France \\ ${ }^{\mathrm{d}}$ LUNAM Université, Université de Nantes, CNRS, LTN, UMR6607, BP 50609, 44306 Nantes, France
}

\begin{abstract}
Previous studies have shown the feasibility of food foam production in a SMX10 static mixer. Nevertheless the void fraction, $\alpha$, obtained was high $(>0.85)$ compared to the target range in food industry $(0.5-$ 0.7 ). This work aims to reduce $\alpha$ by using a smaller hydraulic diameter of the static mixer (SMX+6) and higher liquid base viscosities. The hydrodynamic study exhibits slight differences in the pressure drop and process shear constants. The foams are processed with a liquid base of whey protein isolates (3\%) and xanthan gum $(0.35 \%$ or $0.6 \%)$. The boundaries between "slug flow" and "bubble flow" are determined for the two SMX and represented in a flow pattern map. Only the latter flow regime is suitable as $\alpha$ (0.73-0.96) can directly be controlled from the flow-rates. Working with a SMX+6 mm offers a substantial enlargement of the convenient velocity range that allows attaining lower void fractions compared to the SMX10.
\end{abstract}

\section{Introduction}

Food foams such as foams based on proteins are in constant development, as they are appreciated by the consumers and offer a wide range of possibilities to suit a variety of tastes, textures, or nutritional allegations (Campbell and Mougeot, 1999). In most cases for food foams, the foaming processes are carried out in batch in table top mixers. According to Campbell and Mougeot (1999), the void fraction of foams usually ranges from 0.5 for chocolate foams or ice creams to 0.7 for whipped creams (Chantilly). Yet, continuous processes bring significant benefits: high productivity, homogeneous shearing, small size of the equipment, energy saving and easy-to-monitor systems (Thakur et al., 2003a. Al Taweel and Chen, 1996; Al Taweel et al., 2007). However, continuous foaming is relatively poorly understood and the current knowledge is mostly empirical.

There are two types of continuous foaming processes. The first type is "dynamic mixers", such as rotor-stator systems (Mondo$\mathrm{mix}^{\mathrm{TM}}$, for one of the most widespread use in the industry), scraped-surface heat exchanger, or even the foaming column developed by Djelveh et al. (1998) and Souidi et al. (2012). The second one is "static mixers", consisting of inserts in the flow section, namely "elements", generating complex flow structure to create

\footnotetext{
* Corresponding author. Tel.: +33 (0)240 172 677; fax: +33 (0)240 172618 .

E-mail address: agnes.montillet@univ-nantes.fr (A. Montillet).
}

the mixing. There are different shapes of static mixers but the cross designed ones, of SMX type, outperform the others, especially in the laminar regime (Meijer et al., 2012. Fradette et al., 2006). Static mixers are usually used for liquid-liquid extraction, liquid-gas absorption, heterogeneous chemical reactions, suspensions, emulsification or solid-liquid mixing (Paglianti, 2008). In the suitable foaming conditions, the main asset of static mixers is that the gas incorporated in the foam can directly be controlled from the flow-rates (Talansier, 2009), which is not the case in most of the other foaming processes. For example, the amount of gas incorporated with the Mondomix ${ }^{\mathrm{TM}}$ is only $30-80 \%$, which makes it impossible to master the amount of overrun (Thakur et al., 2003b, 2005).

In a previous study displaying the opportunity to produce food foams with a static mixer, it has been shown that foams from egg white proteins can be produced in a SMX10 static mixer for void fractions (i.e. gas volume fractions) above 0.85 , i.e. corresponding to dry foams (Talansier et al., 2013). However, as mentioned above, food foams are usually liquid foams with void fractions lower than 0.8 . Actually, a key parameter for industrial foams is the stability, whereby smaller bubbles as well as higher void fractions improve the foam stability (Talansier et al., 2013). The challenge of overrun reduction (less than 0.85 , compared with the previous runs in the SMX10 with egg white proteins), appears at first sight to be delicate, as it will affect the structural and textural characteristics of a foam with a negative effect on the stability. Literature reports that it is necessary to increase either the shear rates or/and the 
liquid viscosity to compensate for it (Hanselmann and Windhab, 1999; Mary, 2011; den Engelsen et al., 2002).

The determination of the conditions that are required to achieve the gas mixing in the main liquid flow, i.e., the flow pattern, is crucial in the industrial process control for both dynamic and static mixers. In a biphasic gas/liquid flow, the two phases distribute themselves into several distinct flow patterns depending upon their flow-rates, properties and pipe geometry (Kleinstreuer, 2003). These are referred to as flow regimes, mainly the annular, slug/plug and bubble regimes that are recognized by visual inspection. There have been several experimental works on the gasliquid flow patterns in horizontal pipes (Baker, 1954. Mandhane et al., 1974; Wong and Yau, 1997). However, the frontiers between the different regimes cannot be expressed by the same dimensionless numbers, despite the different attempts to establish universal maps (Schicht, 1969; Taitel and Dukler, 1976; Barnea et al., 1980; Spedding and Chen, 1981; Lin and Hanratty, 1987). Different studies oriented toward fluid properties have been published; nevertheless, very few investigations were conducted on the effect of the fluid viscosity in the case of flow through horizontal pipes. Studies concerning high fluids viscosity came up with contradictory conclusions: Matsubara and Naito (2011) stated that the regimes are affected by the viscosity, whereas Weisman et al. (1979) reported only minor changes induced by this parameter. A decrease in the surface tension shifts the frontiers to lower gas velocity (Spedding and Hand, 1997. Wilkens et al., 2006) but this effect vanishes at high gas velocities (Tzotzi et al., 2011)). Therefore, additional work is required for the understanding of the flow pattern maps, especially in a complex geometry such as the SMX, generating elongational effects that are not present in empty plain tubes (Bone, 2005).

In this study, we propose to investigate the effect of the flow conditions and of the liquid base properties in two SMX static mixers characterized by different hydraulic diameters. The experiments are designed to determine the flow process conditions in SMX static mixers enabling formation of foams at lower void fractions. Firstly, a hydrodynamic study is performed through the determination of the respective characteristic constants: $K_{p}$, the power constant, and $K s$, the shear rate constant evaluated by the Metzner-Otto method (Metzner and Otto, 1957). The hydrodynamic conditions allowing complete and homogeneous gas incorporation and corresponding to the bubble regime are experimentally determined, by varying the gas and liquid flowrates for each tested solution. Foams are made of whey protein isolates (WPI) as foaming agent and xanthan gum (XG) at different concentrations to modulate the liquid viscosities, elucidating the effect of liquid base viscosities on the flow pattern.

\section{Experimental facility and methods}

\subsection{SMX static mixers}

The foams are elaborated by gas injection in a continuous flow of liquid using the static mixers SMX ${ }^{\mathrm{TM}}$ or SMX+TM (Sulzer, Winterthur, Switzerland). They have a respective inside diameter of 10 and $6 \mathrm{~mm}$ in diameter. One element of SMX consists of stainless steel crossed bars at angles of $45^{\circ}$ over flow direction with ratios of length to diameter equal to one. Each element is rotated $90^{\circ}$ prior to the previous element. Characteristics of the static mixers geometry are given in Table 1.

\subsection{Hydraulic loop}

The elements of static mixers are included in the hydraulic loop shown in Fig. 1. A gas injection device has been designed to feed the static mixer section with air. It is located immediately upstream the first element of static mixer. Its specific geometry ensures that the gas is well dispersed all around the pipe diameter: the gas is introduced in the liquid by an annular dispenser with 12 tubular holes symmetrically located around the section. The injection holes are $0.5 \mathrm{~mm}$ in diameter for SMX10 and $0.3 \mathrm{~mm}$ in diameter for $\mathrm{SMX}+6$.

The experimental loop includes a screw pump (Lenze ${ }^{\mathrm{TM}}$ ) to feed the static mixer with the liquid, as well as a liquid flow-meter and a gas mass flow-meter (Proline Promag 50 and Promass 80 from Endress + Hausser ${ }^{\mathrm{TM}}$ ). Two pressure sensors, Ceraphant $\mathrm{T}$ and Deltabar $\mathrm{S}$ (Endress + Hausser ${ }^{\mathrm{TM}}$ ), with adjusted measuring range until 3 bars, are located at the gas inlet and at the bounds of the static mixer to measure the pressure drop across the mixer. Thermocouples (Type K, Omega ${ }^{\circledR}$ ) are used to record the temperatures of liquid and foam.

\subsection{Fluids: whey protein - xanthan gum solutions}

\subsubsection{Composition and preparation}

The liquid phase consists of Whey Protein Isolate (WPI) (Lactalis Ingredients, Bourbarré, France) with $95 \mathrm{wt} \%$ protein as surfaceactive agent and Xanthan Gum (XG) (Cargill, Baupte, France) acting as a thickener. Two WPI-XG solutions are prepared from $3 \mathrm{wt} \%$ WPI, and 0.35 and 0.6 wt\% xanthan gum, referred to as WPI3XG35 and WPI3XG06 respectively. A third solution is obtained by adding $\mathrm{NaCl}(0.2 \mathrm{M})$ to WPI3XG035 to test the eventual effect of the ionic strength on the conformation of the protein and/or xanthan gum. These concentrations correspond to the ones used in the milk industry (Fox and McSweeney, 2003; Simon, 2001). For these concentrations, the two biopolymers are non-interacting and mutually soluble in the water (Benichou et al., 2007).

Dispersions are obtained using the following procedure. Batches of $20 \mathrm{~L}$ are prepared in a cylindrical mixing vessel (Guedu, Lavergne, France). Powders of WPI and xanthan are dispersed in water, at a controlled temperature $\left(40^{\circ} \mathrm{C}\right)$ and at $\mathrm{pH} 7$, by the addition of $0.1 \mathrm{M} \mathrm{NaOH}$ solution, for better protein solubilization (Guimarães Pelegrine and De Moraes Santos Gomes, 2008). Stirring is carried out at low speed ( $50 \mathrm{rpm}$ ) to prevent formation of foam, during five hours, and then the batches are kept at $4{ }^{\circ} \mathrm{C}$ to ensure complete hydration of the polymers

\subsubsection{Viscosity and surface tension}

The viscosity of the WPI-XG mixtures is determined for each batch using the AR-1000N rheometer (TA Instruments, USA) with cone-plate geometry $\left(60 \mathrm{~mm}\right.$ diameter, $4^{\circ}$ cone angle) at $25^{\circ} \mathrm{C}$. Shear rate $\dot{\gamma}$ ranged between $0.2 \mathrm{~s}^{-1}$ and $2800 \mathrm{~s}^{-1}$. The viscosity of the solutions is affected by the XG concentration, and the addition of sodium chloride decreases the viscosity. These solutions exhibit a shear thinning behavior as seen in Fig. 2 and can be fitted with a power law for shear rates between 0.3 and $700 \mathrm{~s}^{-1}$.

$\mu=K \dot{\gamma}^{n-1}$

where $\tau$ is the shear stress, $K$ is the flow consistency index and $n$ the structure index.

The interfacial tension $\sigma$ of the test solutions ( $3 \mathrm{wt} \% \mathrm{WPI}$ ) was measured with a K12 tensiometer (Krüss GmbH, Germany) using the Wilhelmy's plate method at $20^{\circ} \mathrm{C}$ during $3 \mathrm{~h}$. With a constant WPI concentration, the interfacial tension is $43 \pm 1 \mathrm{mN} \mathrm{m}^{-1}$ at long time (equilibrium value) for all the solutions. Neither xanthan gum nor sodium chloride changes the interfacial tension. The composition and properties of the solutions are gathered in Table 2. 
Table 1

Characteristic values of Sulzer SMX10 and SMX+6.

\begin{tabular}{|c|c|c|}
\hline Characteristic values & SMX10 & SMX+6 \\
\hline Number of elements, $n_{e}(-)$ & 25 & 10 \\
\hline Pipe diameter, $D(\mathrm{~m})$ & 0.010 & 0.006 \\
\hline Total length, $L(\mathrm{~m})$ & 0.25 & 0.06 \\
\hline Hydraulic diameter, $D_{h}(\mathrm{~m})$ from Sulzer & 0.00265 & 0.0018 \\
\hline Porosity, $\varepsilon(-)$ & 0.77 & 0.77 \\
\hline
\end{tabular}

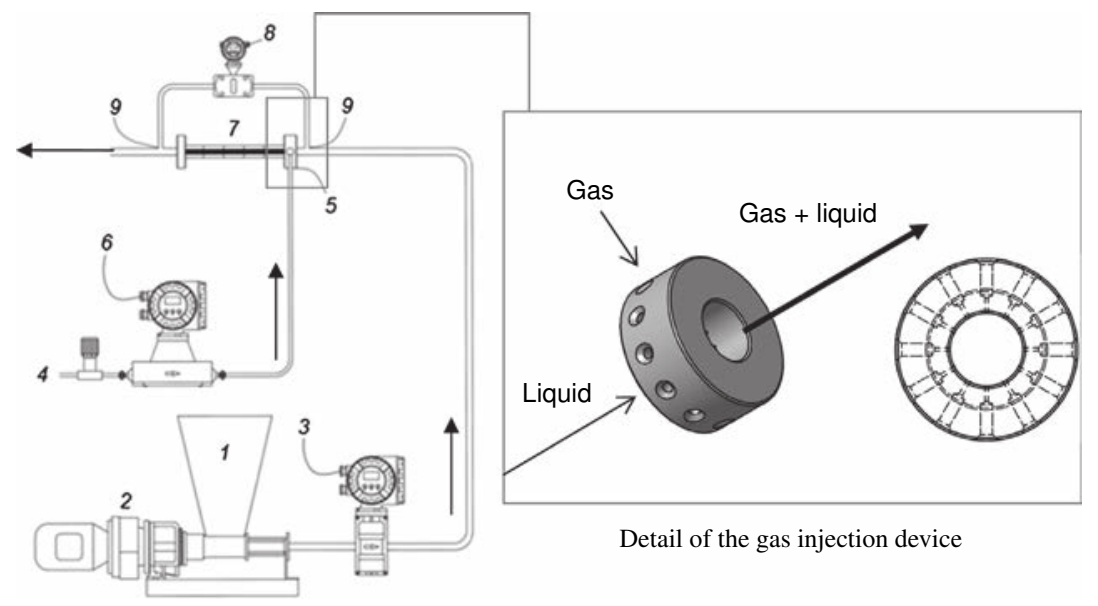

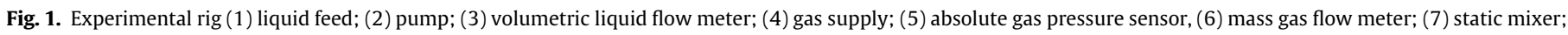
(8) differential pressure sensor; (9) temperature sensors. The gas injection device is zoomed on the right of the figure.

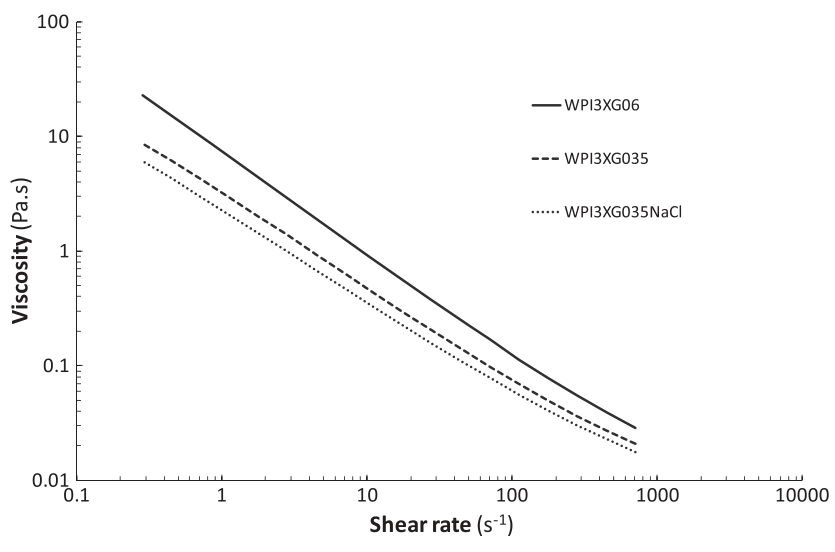

Fig. 2. Flow curves of the WPI-XG liquid solutions, $20^{\circ} \mathrm{C}$.

\subsection{Foam void fraction}

In the perfectly dispersed regime, assuming a no-slip velocity between the two phases, the void fraction $\alpha$ is determined from the input liquid and gas volumetric flow-rates, respectively $Q_{\text {liquid }}$ and $Q_{g a s}$, as follows:

$\alpha_{\text {theoretical }}=\frac{Q_{\text {gas }}}{Q_{\text {gas }}+Q_{\text {liquid }}}$

The experimental void fraction is deduced from the amount of gas incorporated in the foam. It is calculated from the weight, $W_{l}$, of the liquid solution filling a receptacle of given volume and that, $W_{f}$, of the foam filling the same receptacle. The deviation is $0.5 \%$.

$\alpha_{\text {exp erimental }}=\frac{W_{l}-W_{f}}{W_{l}}$

Table 2

Composition and properties of liquid solutions at $25^{\circ} \mathrm{C}$.

\begin{tabular}{|c|c|c|c|c|c|c|c|c|}
\hline $\begin{array}{l}\text { Reference of the liquid } \\
\text { solution }\end{array}$ & WPI (wt\%) & XG (wt\%) & $\mathrm{NaCl} 0.2 \mathrm{M}$ (wt\%) & $\rho_{l}\left(\mathrm{~kg} \mathrm{~m}^{-3}\right)$ & $\begin{array}{l}K\left(\operatorname{Pa~s}^{n}\right) \\
\text { Eq. }(1)\end{array}$ & $\begin{array}{l}n(-) \\
\text { Eq. (1) }\end{array}$ & $\begin{array}{l}\text { Difference between experiments } \\
\text { and model (\%) }\end{array}$ & $\sigma_{l}\left(\mathrm{mN} \mathrm{m}^{-1}\right)$ \\
\hline WPI3X06 & 3 & 0.60 & 0 & 1036 & $7.2 \pm 0.4$ & $0.12 \pm 0.01$ & 5.6 & $43 \pm 1$ \\
\hline WPI3X035 & 3 & 0.35 & 0 & 1034 & $3.1 \pm 0.2$ & $0.21 \pm 0.01$ & 4.9 & $43 \pm 1$ \\
\hline WPI3X035NaCl & 3 & 0.35 & 1.2 & 1046 & $2.2 \pm 0.2$ & $0.24 \pm 0.01$ & 5.6 & $43 \pm 1$ \\
\hline
\end{tabular}




\section{Results and discussion}

\subsection{Hydrodynamic conditions}

\subsubsection{Pressure drop in the SMX static mixers}

The power consumption in monophasic steady-state flow can be quantified in terms of the Fanning friction factor $f$, which is related to the only Reynolds number. The friction factor, $f$, is defined as:

$f=\frac{\Delta P}{2 \rho U_{s}^{2}} \frac{D}{L}$

where $D$ is the tube diameter, $L$ the total length of the static mixers, $\Delta P$, the pressure drop, $U_{s}$ the superficial velocity, i.e. the average velocity in the empty duct. $\rho$ and $\mu$ are respectively the density and the viscosity of the fluid.

The Reynolds number, Re, is defined as:

$\operatorname{Re}=\frac{U_{s} \rho D}{\mu}$

The evolution of the friction factor versus Reynolds number can be represented by Eq. (6). $K_{p}$ and $C$ are two constants which only depend on the geometry shape, and hence are supposed to be invariant in a scale-up of static mixers:

$f=\frac{K_{p}}{2 \operatorname{Re}}+C$

The pressure drop measurements are carried out with sunflower oil and a solution of glycerol $25 \mathrm{w} / \mathrm{w} \%$ (see properties in Table 3 ) to determine $K_{p}$ and $C$ values. Fig. 3 displays the friction factor curve obtained for these fluids versus the Reynolds numbers. The values of $K_{p}$ and $C$, including their mean relative errors, are provided in Table 4 for the two SMX mixers. These values are in agreement with the literature values (Hirschberg et al., 2009). It is observed that the pressure drop factor in the SMX+6 is lower than for the standard SMX10 at a given Reynolds number, due to a slightly different geometry. Therefore, there is a certain compensating effect on the pressure drop increase at a given flow-rate, when switching from the SMX10 to the SMX+6.

\subsubsection{Determination of process shear rate in the SMX static mixers}

Metzner and Otto (1957) established a simple method to evaluate the shearing level in stirred tanks, based on a scale law of the process shear, $\dot{\gamma}_{a p p}$. The Metzner Otto constant, $K_{s}$, has to be determined experimentally in order to evaluate the apparent shear rate $\dot{\gamma}_{\text {app }}$ from the rotation frequency, $N$, in the stirred tank:

$\dot{\gamma}^{n}=K_{s} N$

A similar law can also be used to determine the effective shear rate in static mixers, replacing the number of rotations per unit time, $N$, by the ratio of superficial fluid velocity and pipe diameter, $U_{s} / D$ as proposed by Alonso et al. (2000):

$\dot{\gamma}_{a p p}=K_{s} \frac{U_{s}}{D}$

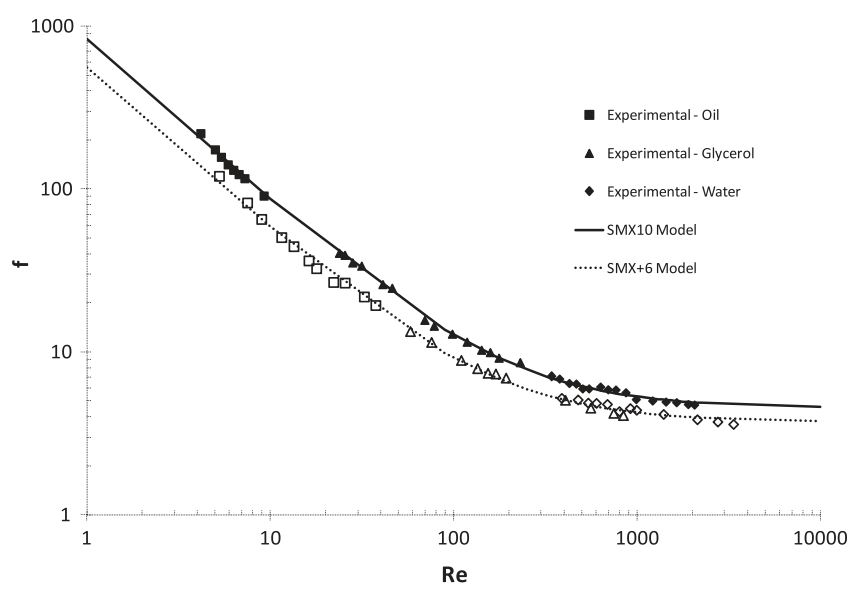

Fig. 3. Experimental data (symbols - hollow for SMX+6 and full for SMX10) and power characteristic model (lines - dotted for SMX+6 and solid for SMX10).

Table 4

Characteristic hydrodynamical constants of SMX10 and SMX+6.

\begin{tabular}{lllll}
\hline SMX & $K_{p}$ & $C$ & Experiment-model deviation (\%) & $K_{s}$ \\
\hline SMX+6 & 1100 & 3.7 & 3.7 & $16 \pm 1$ \\
SMX10 & 1650 & 4.5 & 3.3 & $24 \pm 2$ \\
\hline
\end{tabular}

The method consists of determining the shear rate through the viscosity $\mu$ of a non-Newtonian fluid following a given Ostwald-de Waele rheological behavior (Chhabra and Richardson, 2008):

$\mu=K \dot{\gamma}_{a p p}^{n-1}$

By representing the experimental variation of friction factor versus generalized Reynolds number (Eq. (10)) in laminar flow $(\operatorname{Re}<50)$, one obtains a friction factor curve that is shifted from the reference Newtonian curve by a factor $K_{s}^{n-1}$. The gap between the two curves, i.e. the factor $K_{s}^{n-1}$, can be determined in log scale.

$\operatorname{Re}_{g}=\frac{U_{s}^{2-n} \rho D^{n}}{K}$

Then, merging the curves into a single calibration curve is achieved using the effective Reynolds number:

$\operatorname{Re}_{e f f}=\frac{U_{s}^{2-n} \rho D^{n}}{K K_{s}^{n-1}}$

Here, the solutions of guar gum, $0.35 \mathrm{wt} \%$ and $0.5 \mathrm{wt} \%$ are used as non-Newtonian fluid; their rheological properties are listed in Table 3. Experimental results are shown in Fig. 4, where the friction factor $f$ is plotted as a function of the effective Reynolds number, $\mathrm{Re}_{\text {eff. }}$ The curves match in the range of Reynolds number below 15 for $K_{s}=16$.

Concerning the SMX10, previous experiments allowed to determine a value of $K_{s}$ equal to 24 (Bone, 2005). It can be observed that the value of $K_{s}$ corresponding to the SMX+6 is lower than that of

Table 3

Properties of fluids at $20^{\circ} \mathrm{C}$.

\begin{tabular}{|c|c|c|c|c|}
\hline Solution & $\rho\left(\mathrm{kg} \mathrm{m}^{-3}\right)$ & $\mu$ (Pa s) Eq. (1) & & \\
\hline Guar 0.5 wt\% & 1005 & Non Newtonian $\left(10<\dot{\gamma}<2000 \mathrm{~s}^{-1}\right)$ & $K=1.29 \mathrm{~Pa} \mathrm{~s}^{n}$ & $n=0.48$ \\
\hline Guar 0.35 wt\% & 1003 & Non Newtonian $\left(10<\dot{\gamma}<2000 \mathrm{~s}^{-1}\right)$ & $K=0.32 \mathrm{~Pa} \mathrm{~s}^{n}$ & $n=0.65$ \\
\hline Sunflower oil & 910 & Newtonian & $K=0.0670 \mathrm{~Pa} \mathrm{~s}$ & $n=1$ \\
\hline Glycerol 25 wt $\%$ & 1060 & Newtonian & $K=0.0043 \mathrm{~Pa} \mathrm{~s}$ & $n=1$ \\
\hline Water & 1000 & Newtonian & $K=0.0010 \mathrm{~Pa} \mathrm{~s}$ & $n=1$ \\
\hline
\end{tabular}




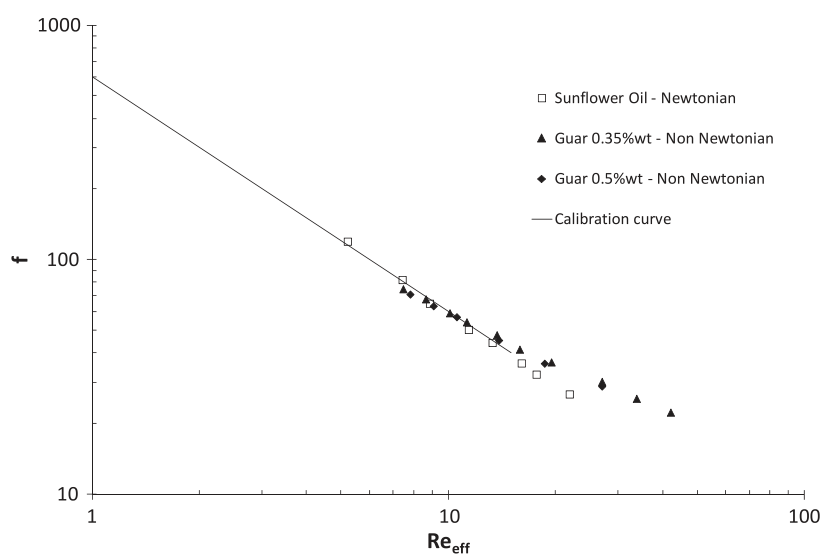

Fig. 4. Friction factor versus effective Reynolds number in the $S M X+6$ with flow of sunflower oil (hollow symbols) and guar solutions (full symbols).

SMX10. This obviously confirms the fact outlined in Section 3.1.1 with the lower pressure drop constant. This implies that, at a given flow-rate per unit surface, a lower level of shear is achieved in the $\mathrm{SMX}+6$. However, the process shear rate $\dot{\gamma}_{\text {app }}$ is higher in the SMX+6 for a given flow rate due to the smaller section.

\subsubsection{Dimensional process shear rate}

The apparent shear rate in foaming condition needs to be evaluated as it is a strategic parameter for mixing and gas bubbles breakup. However, its determination from Eq. (8) is only valid in creeping flow. The dimensional range of process shear rate is presented in Fig. 5 as a function of Reynolds numbers for the two SMX, as far as the Reynolds number value indicates the reliability of the shear rate model in the range of operating conditions. The curves are plotted for two fluids of different properties, one is a monophasic oil (glycerol solution $25 \mathrm{wt} \%$ ), and the other is a typical foam of 0.8 void fraction, by considering the density, $\rho_{f}$, as $(1-\alpha) \rho_{l}$ and the velocity, $U_{s}$, is the sum of liquid $U_{l}$ and gas $U_{g}$ velocities. The viscosity used in the Reynolds number is of the order of magnitude taken from our experiments, about 0.1 Pa s nearly constant for the whole flow rates range. This diagram shows that even with the highest flow-rates (gas and liquid) encountered in this study, the flow is laminar, which justifies the use of the process viscosity calculation.

\subsubsection{Energetical efficiency}

Some insights in the mixers energy efficiency can be provided by the ratio of the apparent shear rate $\dot{\gamma}_{a p p}$ to the specific energy $E$ (per unit mass) required for the foaming. This specific energy is

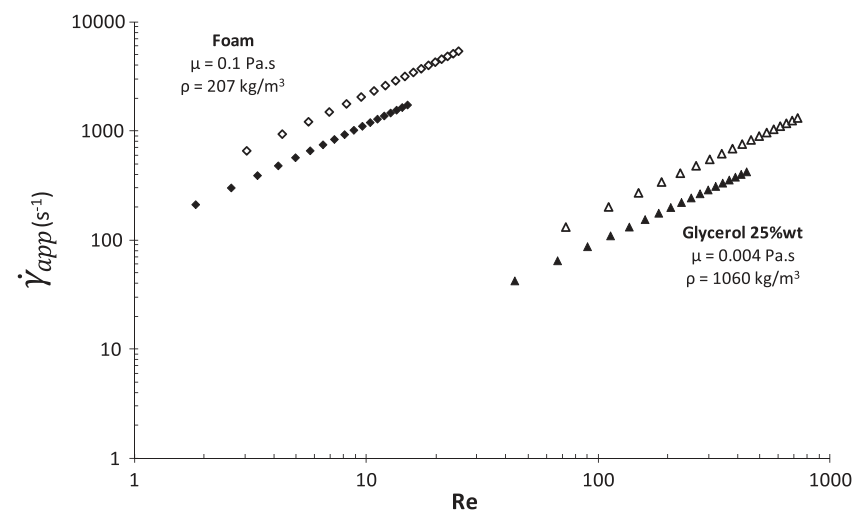

Fig. 5. Evolution of apparent shear rates in SMX+6 (hollow symbols) and SMX10 (full symbols) respectively with flow of foam ( $\downarrow, \alpha=0.8$ and $\mu=0.1$ Pa s) and flow of a glycerol solution $(\boldsymbol{\Lambda})$ versus Reynolds numbers. defined as the ratio of the pressure drop, $\Delta P$, to the foam density, $\rho$. From Eqs. (4), (6), and (8), the SMX efficiency is expressed as:

$\frac{\dot{\gamma}_{a p p}}{E}=\frac{\rho}{\mu} \frac{K_{s}}{K_{p}} \frac{D}{L}$

This efficiency factor, as shown in Eq. (13), only depends on the $K_{p}$ and $K_{s}$ values and on the shape ratio, allowing a comparison between the two mixers for a given processed fluid but independently of the operating conditions. The ratio of the respective efficiency factors for the two devices reads:

$\frac{\left(\frac{\dot{\gamma}_{a p p}}{E}\right)_{S M X+6}}{\left(\frac{\dot{\gamma}_{a p p}}{E}\right)_{S M X 10}}=\frac{\left(\frac{K_{s}}{K_{p}} \frac{D}{L}\right)_{S M X+6}}{\left(\frac{K_{s}}{K_{p}} \frac{D}{L}\right)_{S M X 10}}$

The efficiency related to the SMX+6 is higher than the one in the SMX10 by a factor of 2.85 . This gives an advantage for using the $\mathrm{SMX}+6$ in the sense that the energy consumption is less for reaching the same shear rate. It also means that the length of the SMX+6 used in this study $(0.06 \mathrm{~m})$ could be increased up to $0.15 \mathrm{~m}$ while still maintaining the same efficiency as opposed to the SMX10 of $0.25 \mathrm{~m}$ length. This could be taken into account according to the effect of the residence time towards the bubble breakup and the final bubble foam diameter.

\subsection{Flow pattern map}

The experiments aimed to determine the flow transition are carried out in the SMX10 and in the SMX+6, with a reference method to avoid any hysteresis effect. For a given value of the liquid flow-rate in the range [8-50] $\mathrm{L} / \mathrm{h}$, the gas flow-rate is decreased monotonically starting from the maximum value, where the slug flow is generally observed. The tested range of gas flow-rate is [0.02-0.45] $\mathrm{Nm}^{3} / \mathrm{h}$. Once the gas plugs disappear, the corresponding gas flow-rate is recorded as well as pressure drop and gas injection pressure. Limits between the regimes are visually determined at the outlet of the static mixers.

The flow pattern map coordinates $\left(U_{s, l}, U_{s, g}\right)$ presented in Fig. 6 , are established from eight flow-rates pairs $\left(Q_{l}, Q_{g}\right)$ and for three liquid solutions. In the present study, the plotted frontier corresponds to the transition between the two flow regimes observed within the experimental range, which are the "dispersed" regime that allows a complete incorporation of the gas, and the so called "slug flow" regime that occurs at high gas flow-rates. Other types of existing flow patterns (plug, annular, stratified, etc.) are not observed over the present range of conditions. Theoretical foam void fractions are mentioned on the maps by contours of iso-values; they are straightforwardly deduced of the flow-rates, but of course the validity is limited to the bubble regime area. Some representative experimental values taken at the frontiers are gathered in Table 5. Operating with a set of velocities located at the left of the limit will ensure that there is no gas loss in the process, and hence a better process yield. Increasing the gas velocity beyond the frontier results in a gas waste, then the foam void fraction cannot be controlled. The limits obtained for SMX10 and SMX+6 seem to be consistent with the previous hydrodynamic study: for a given liquid matrix the dispersed regime is reached for a higher gas flow-rate in the case of a smaller hydraulic diameter in the SMX+6. Thus, reducing the SMX diameters does not induce radical changes in the flow map frame, so that no particular issues are brought to light in the scale-down. It can also be observed that the limit shifts toward lower gas velocity with increasing liquid phase viscosity. Most experiments have been made in triplicate in the case of SMX10 and are at least doubled in the case of SMX+6 (ranges of deviation are shown for each flow condition in Fig. 6). Repeat experiments show a 5\% standard deviation for the 


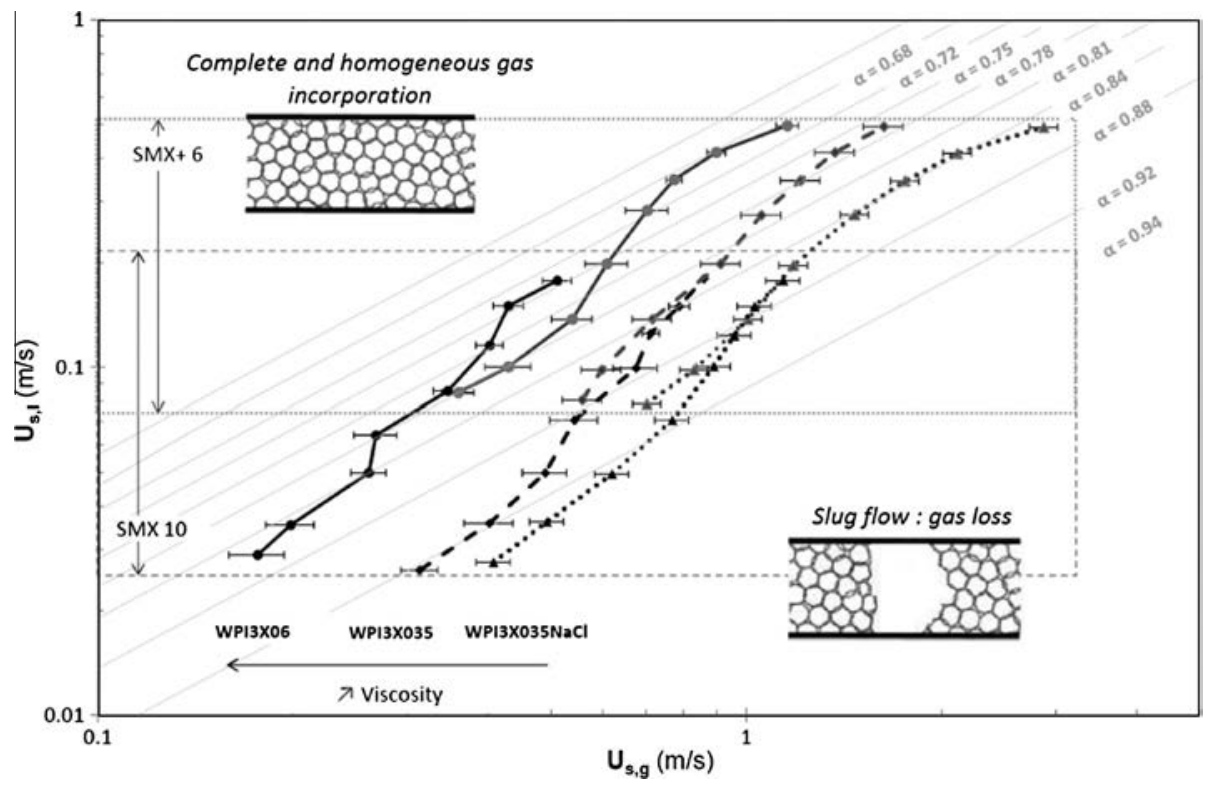

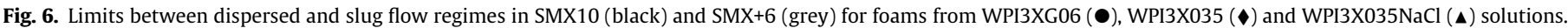

Table 5

Experimental conditions for few runs.

\begin{tabular}{|c|c|c|c|c|c|c|}
\hline SMX & $Q_{l}(\mathrm{~L} / \mathrm{h})$ & $Q_{g}\left(\mathrm{Nm}^{3} / \mathrm{h}\right)$ & $f$ (calculated from Eq. (8)) & $\operatorname{Re}$ & $\dot{\gamma}_{a p p}\left(\mathrm{~s}^{-1}\right)$ & $\alpha_{\max }$ \\
\hline \multicolumn{7}{|c|}{ WPI3XG035NaCl } \\
\hline \multirow[t]{3}{*}{ SMX10 } & 8 & 0.116 & 333 & 2.3 & 360 & 0.94 \\
\hline & 28 & 0.254 & 66 & 12 & 800 & 0.90 \\
\hline & 50 & 0.325 & 34 & 25 & 1100 & 0.87 \\
\hline \multirow[t]{3}{*}{$\mathrm{SMX}+6$} & 8 & 0.072 & 102 & 6 & 870 & 0.90 \\
\hline & 28 & 0.143 & 37 & 18 & 1740 & 0.83 \\
\hline & 50 & 0.295 & 16 & 46 & 3100 & 0.85 \\
\hline \multicolumn{7}{|c|}{ WPI3XG035 } \\
\hline \multirow[t]{3}{*}{ SMX10 } & 8 & 0.090 & 389 & 1.9 & 300 & 0.92 \\
\hline & 28 & 0.195 & 73 & 11 & 690 & 0.87 \\
\hline & 50 & 0.248 & 38 & 22 & 970 & 0.83 \\
\hline \multirow[t]{3}{*}{$\mathrm{SMX}+6$} & 8 & 0.058 & 101 & 6.1 & 760 & 0.87 \\
\hline & 28 & 0.110 & 30 & 23 & 1510 & 0.79 \\
\hline & 50 & 0.170 & 18 & 41 & 2370 & 0.77 \\
\hline \multicolumn{7}{|c|}{ WPI3XG06 } \\
\hline \multirow[t]{3}{*}{ SMX10 } & 8 & 0.050 & 372 & 2.1 & 220 & 0.86 \\
\hline & 28 & 0.104 & 86 & 9.2 & 520 & 0.80 \\
\hline & 50 & 0.144 & 42 & 20 & 770 & 0.74 \\
\hline \multirow[t]{3}{*}{ SMX+6 } & 8 & 0.038 & 84 & 7.4 & 580 & 0.82 \\
\hline & 28 & 0.074 & 27 & 25 & 1330 & 0.72 \\
\hline & 50 & 0.121 & 16 & 47 & 2180 & 0.71 \\
\hline
\end{tabular}

gas flow-rate at the transition, while there is less than $1 \%$ standard deviation regarding liquid flow-rates uncertainty.

From these results, an attempt is made to gather the combined effects of the liquid solution viscosity and the operating conditions on the regime transition and the maximum void fraction attainable in the bubble regime. The global capillary number $\mathrm{Ca}$ is introduced, corresponding to the ratio between a viscous stress scale $\left(U_{s, l} \mu_{l}\right) / D_{h}$ and a surface forces scale $\sigma_{l} / D_{h}$ :

$\mathrm{Ca}=\frac{U_{s, l} \mu_{l}}{\sigma_{l}}$

In Fig. 7, the evolution of this maximum void fraction versus the corresponding capillary number seems to correlate the results for all the tested solutions. It clearly shows that the maximum void fraction decreases with increasing liquid viscosity, for the two SMX. The data merge onto a single curve for each SMX, the lower level for the SMX+6 being explained by the lower $K_{S}$ in this device, compared to the SMX10. Concomitantly, for higher capillary numbers (high liquid viscosities), the dynamic conditions are more favorable for the bubble breakup, that contributes to the foam stability (Zaki et al., 2002). It is important to note here that the upper limit of the void fraction remains compatible with the food foams specifications. The correlation proposed in Fig. 7 is also valid concerning the data from Talansier (2009) and obtained in SMX10 respectively with egg white and with glucose syrup $60 \mathrm{wt} \%$ mixed with Tween $200.1 \mathrm{wt} \%$. It might be emphasized that these solutions exhibited different values of the interfacial tension than that of the presently tested solutions.

In the case of the SMX+6, it is possible to reach higher capillary numbers and then to produce finer bubbles and more stable foams on a limited extent. In that sense, the initial objective of reducing the void fraction with a smaller hydraulic diameter and higher 


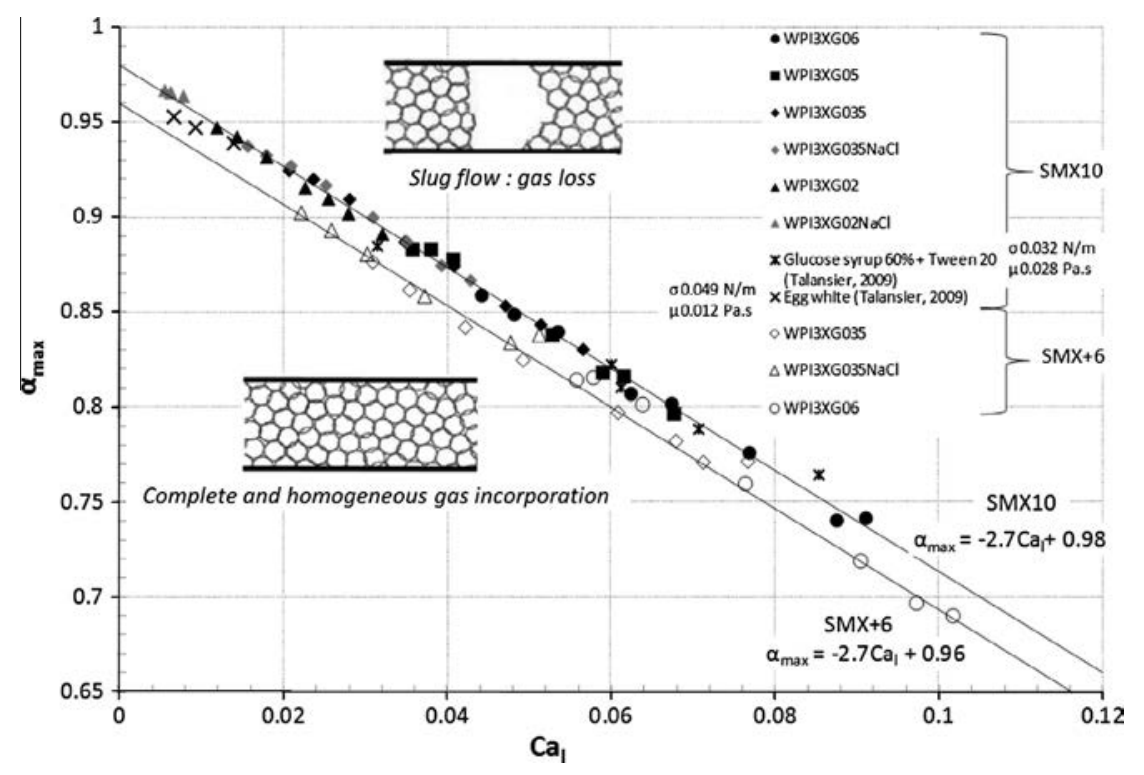

Fig. 7. Maximum void fraction, $\alpha_{\max }$, available for different liquid capillary numbers, $C a_{l}$ in the SMX+6 (hollow symbols) and in the SMX10 (full symbols).

fluid viscosities can be fulfilled, with the drawback of a certain limitation of the void fractions. The chart shown in Fig. 7 can be used to quantify this feature. For a complete knowledge of the process, this representation can be further developed with the lower limit of void fractions corresponding to convenient foam structure, and provide a sizing tool for the foaming process in the SMX. It might be emphasized that literature models, referred to in Section 1, fail to predict the flow regime transitions in the case of the presently tested two-phase gas-liquid systems. In particular, the models of Taitel and Dukler (1976) and Baker (1954), which are the most quoted in the literature for horizontal tubes, give contradictory predictions that are not in agreement with the present experiments in the SMX. Two reasons may explain the observed discrepancies: literature models concerns only plain tubes and secondly have not been built from data obtained with fluids like these tested in this work. As a conclusion, experiment still remains necessary to bound process conditions.

\section{Conclusions}

WPI and XG foams were produced in SMX10 or SMX+6. The hydrodynamic studies allowed determining the values of the power constant $K_{p}$ and that of process shear rate coefficient $K_{s}$. The values showed a pressure drop reduced with the SMX+6. This means the effect of processing with higher flow-rates in SMX+6 will not increase appreciably the pressure drop.

The respective effect of the gas and liquid flow-rates, of the hydraulic diameter and of the liquid solution viscosities on the dispersed and plug-flow regimes transition were also experimentally investigated. The two-phase flow experiments were performed over a wide range of gas and liquid flow-rates with three liquid solutions of different viscosities. The flow map highlighted a significant flow-rate range in which gas incorporation is fully achieved. The viscosity of liquid solution strongly affects the position of the frontier between flow regimes. The limit shifts towards smaller superficial gas velocities with increasing viscosity as clearly shown with the introduction of a liquid capillary number. Therefore, the maximum void fraction attainable is lower with higher liquid viscosity. The difference in the SMX geometry, characterized by a different hydraulic diameter, does not significantly affect the shape of the flow pattern frontiers: it can be observed that the frontiers are rather continuous in the explored domain of flow-rates. The maximum void fraction attainable is slightly lower with the SMX+6, but remains sufficient for food foams applications.

This study allowed determining suitable foaming conditions with control of foam void fraction. This work constitutes a basis, for, in a next step, focus on process-product interactions and resulting foam properties like bubble size, rheology and stability.

\section{References}

Alonso, S., Tanguy, P.A., Réglat, O., Bertrand, F., 2000. Process viscosity in a film coater. Pap. Puu 82, 34-40.

Al Taweel, A.M., Li, C., Gomaa, H.G., Yuet, P., 2007. Intensifying mass transfer between immiscible liquids using screen-type static mixers. Chem. Eng. Res. Des. 85, 760-765.

Al Taweel, A.M., Chen, C., 1996. A novel static mixer for the effective dispersion of immiscible liquids. Trans. IChemE 74, 445-450.

Baker, O., 1954. Simultaneous flow of oil and gas. Oil Gas J. 53, 185-190.

Barnea, D., Shoham, O., Taitel, Y., Dukler, A.E., 1980. Flow pattern transition for gasliquid flow in horizontal and inclined pipes. Int. J. Multiphase Flow 6, 217-226.

Benichou, A., Aserin, A., Lutz, R., Garti, N., 2007. Formation and characterization of amphiphilic conjugates of whey protein isolate.WPI./xanthan to improve surface activity. Food Hydrocoll. 21, 379-391.

Bone, S., 2005. Etude d'un procédé de fabrication de microcapsules par émulsification dans un mélangeur statique. PhD Thesis. Faculté des sciences et des techniques, Université de Nantes, France.

Campbell, G.M., Mougeot, E., 1999. Creation and characterisation of aerated food products. Trends Food Sci. Technol. 10, 283-296.

Chhabra, R.P., Richardson, J.F., 2008. Non-Newtonian Flow and Applied Rheology: Engineering Applications, second ed. Butterworth-Heinemann/IChemE, Elsevier.

Den Engelsen, C.W., Isarin, J.C., Gooijer, H., Warmoeskerken, M.M.C.G., Groot Wassink, J., 2002. Bubble size distribution of foam. Autex Res. J. 2, 14-27.

Djelveh, G., Gros, J.B., Cornet, J.F., 1998. Foaming process analysis for a stirred column with a narrow annular region. Chem. Eng. Sci. 53, 3157-3160.

Fox, P.F., McSweeney, P.L.H., 2003. Protein Composition of Milk. Advanced Dgasy Chemestry, vol. 1, Proteins, third ed., part A, Springer, New York, pp. 140-143.

Fradette, L., Li, H.Z., Choplin, L., Tanguy, P., 2006. Gas/liquid dispersions with a SMX static mixer in the laminar regime. Chem. Eng. Sci. 61, 3506-3518.

Guimarães Pelegrine, D., De Moraes Santos Gomes, M., 2008. Whey proteins solubility curves at several temperatures values. Ciência e Natura 30, 17-25.

Hanselmann, W., Windhab, E., 1999. Flow characteristics and modelling of foam generation in a continuous rotor/stator mixer. J. Food Eng. 38, 393-405.

Hirschberg, S., Koubek, R., Moser, F., Schöck, J., 2009. An improvement of the Sulzer SMX static mixer significantly reducing the pressure drop. In: 13th European Conference on Mixing. London.

Kleinstreuer, C., 2003. Two-Phase Flow: Theory and Applications, first ed. Taylor and Francis, New York.

Lin, P.Y., Hanratty, T.J., 1987. Effect of pipe diameter on flow patterns for air-water flow in horizontal pipes. Int. J. Multiphase Flow 4, 549-563. 
Mandhane, J.M., Gregory, G.A., Aziz, K., 1974. A flow pattern map for gas-liquid flow in horizontal pipe. Int. J. Multiphase Flow 1, 537-553.

Mary, G., 2011. Prise en compte des effets du produit et du procédé au cours de l'opération de foisonnement par battage en continu - Analyse dimensionnelle. PhD thesis. AgroParisTech., France.

Matsubara, H., Naito, K., 2011. Effect of liquid viscosity on flow patterns of gasliquid two-phase flow in a horizontal pipe. Int. J. Multiphase Flow 37, $1277-$ 1281.

Meijer, H.E.H., Singh, M.K., Anderson, P.D., 2012. On the performance of static mixers: a quantitative comparison. Prog. Polym. Sci. 37, 1333-1349.

Metzner, A.B., Otto, R.E., 1957. Agitation of non-Newtonian fluids. AIChE J. 3 (1), 3 10.

Paglianti, A., 2008. Recent innovations in turbulent mixing with static elements. Recents Patents Chem. Eng. 1, 80-87.

Schicht, H.H., 1969. Flow patterns for an adiabatic two phase flow of water and air within a horizontal tube. Verfarenstechnik 3 (4), 153-178.

Simon, J.-L., 2001. Gomme de xanthane: agent viscosant et stabilisant. Techniques de l'Ingénieur, Traité agroalimentaire, F 4 (300), 4-5.

Souidi, K., Mardaru, A., Roudet, M., Marcati, A., Della Valle, D., Djelveh, G., 2012. Effect of impellers configuration on the gas dispersion in high-viscosity fluid using narrow annular gap unit. Part 1: Experimental approach. Chem. Eng. Sci. 74, 287-295.

Spedding, P.L., Chen, J.J.J., 1981. A simplified method of determining flow pattern transition of two-phase flow in a horizontal pipe. Int. J. Multiphase Flow 6, 729731.

Spedding, P.L., Hand, N.P., 1997. A revised analysis of the effect of surfactants on two-phase phenomena in horizontal air-water pipe flow. Dev. Chem. Eng. Miner. Process 5, 267-279.
Taitel, Y., Dukler, A.E., 1976. A model for predicting flow regime transitions in horizontal and near horizontal gas-liquid flow. AIChE J. 22, 47-55.

Talansier, E., 2009. Étude du foisonnement par melangeur statique appliqué à la structuration des mousses de blanc d'oeuf dénaturé par traitement thermique. PhD Thesis. Faculté des sciences et des techniques, Université de Nantes, France.

Talansier, E., Dellavalle, D., Loisel, C., Desrumaux, A., Legrand, J., 2013. Elaboration of controlled structure foams with the SMX static mixer. AIChE J. 59, 132-145.

Thakur, R.K., Vial, C., Djelveh, G., 2003a. Influence of operating conditions and impeller design on the continuous manufacturing of food foams. J. Food Eng. 60, $9-20$.

Thakur, R.K., Vial, C., Djelveh, G., 2003b. Foaming of commercial grade food products in a continuous stirred column. Trans. IChemE, Part A 81, 1083-1089.

Thakur, R.K., Vial, C., Djelveh, G., 2005. Combined effects of process parameters and composition on foaming of dairy emulsions at low temperature in an agitated column. J. Food Eng. 68, 335-347.

Tzotzi, C., Bontozoglou, V., Andritsos, N., Vlachogiannis, M., 2011. Effect of fluid properties on flow patterns in two-phase gas-liquid flowin horizontal and downward pipes. Ind. Eng. Chem. Res. 50, 645-655.

Weisman, J., Duncan, D., Gibson, J., Crawford, T., 1979. Effect of fluid properties and pipe diameter on two-phase flow patterns in horizontal lines. Int. J. Multiphase Flow 5, 437-462.

Wilkens, R.J., Thomas, D.K., Glassmeyer, S.R., 2006. Surfactant use for slug flow pattern suppression and new flow pattern types in a horizontal pipe. J. Fluids Eng. 128, 164-169.

Wong, T.N., Yau, Y.K., 1997. Flow patterns in two-phase air-water flow. Int. J. Heat Mass Transfer 24, 111-118.

Zaki, N.N., Poindexter, M.K., Kilpatrick, P.K., 2002. Factors contributing to petroleum foaming - Part II: synthetic crude oil systems. Energy Fuels 16, 711-717.

8 